\title{
Uma ciência da diferença: sexo e gênero na medicina da mulher*
}

\author{
Maria Amélia Mascarenhas Dantes **
}

Uma ciência da diferença: sexo e gênero na medicina da mulher trata de um tema instigante: como teorias e práticas médicas do século XIX e início do século XX incorporaram os conceitos da diferença biológica entre os sexos e da vocação natural da mulher para a maternidade.

Resultante de pesquisa de doutorado realizada no Instituto de Medicina Social da UERJ, o livro coloca como seu objetivo central detectar a presença destes temas na produção de médicos brasileiros do período. Para tal foi utilizada ampla documentação: teses apresentadas à Faculdade de Medicina do Rio de Janeiro, revistas e livros médicos do período, além de ampla bibliografia secundária.

Trata-se assim de estudo com contribuições para os estudos de gênero, para a história da medicina, mas também para a historiografia brasileira.

A autora, situando-se na área dos estudos antropológicos, trabalha o tema de uma forma que podemos denominar construtivista, considerando os conceitos de sexo, sexualidade, papéis feminino e masculino, como construções histórico-sociais. As ciências, e mais especificamente os conhecimentos médicos, são vistos, assim, como socialmente construídos.

Entre as áreas científicas, sua atenção se volta de forma mais aprofundada para a ginecologia pois, como o livro mostra,

\footnotetext{
* Rohden, Fabíola. Rio de Janeiro, Editora FIOCRUZ, 2001. Recebida para publicação em dezembro de 2002.

** Universidade de São Paulo.
} 
Uma ciência da diferença...

esta disciplina constituiu-se no século XIX, em países europeus, justamente como uma ciência da diferença entre os sexos.

O primeiro capítulo trata do caso europeu, sublinhando como, de forma aparentemente paradoxal, já no período do iluminismo, os princípios igualitários da Revolução Francesa conviveram com discursos que defendiam a diferença biológica portanto essencial - entre mulheres e homens.

Enfatizando a permanência, durante o século XIX de uma multiplicidade de discursos sobre os sexos, a autora mostra como os conceitos da diferença biológica foram apropriados pela nova ciência da mulher, a ginecologia, que passou a defender que características sexuais femininas determinariam não apenas a propensão das mulheres à maternidade, como suas características psicológicas e intelectuais.

O segundo capítulo aprofunda o tema, tratando da institucionalização da ginecologia como disciplina científica e traz uma questão particularmente instigante: a grande atenção dada pelos médicos do século XIX ao estudo das mulheres, comparativamente à dedicada aos homens. Como a autora enfatiza, a obstetrícia desde o século XVIII já se voltava para as questões relativas à gestação, ao parto e ao puerpério. A nova ciência da ginecologia passava a considerar o quadro mais geral das características físicas e mentais das mulheres, vistas como indissoluvelmente ligadas ao papel desempenhado pela função sexual em suas vidas.

Também é bastante esclarecedor o paralelo feito pela autora entre os estudos ginecológicos e os antropológicos sobre as características da espécie humana como um todo, e a conclusão de que ambos contribuíram para o fortalecimento de hierarquias sociais. De um lado, nas relações entre homens e mulheres, de outro, nas relações entre raças e povos.

Passando para o caso brasileiro, a autora constata que, apesar da institucionalização tardia do ensino médico, os campos da ginecologia e da obstetrícia, no país, se constituíram de forma semelhante ao que acontecia na Europa. No entanto, não sem 
resistências, já que a relação entre médico e mulher-paciente continuava bastante problemática durante todo o século XIX.

Nos capítulos 3 e 4 , a autora se dedica ao estudo mais detalhado das teorias e práticas ginecológicas no Brasil no século XIX e início do século XX.

O capítulo 3 focaliza as teses de jovens formandos da Faculdade de Medicina do Rio de Janeiro, ainda pouco utilizadas pela historiografia, mas que, como a autora enfatiza, contando com o respaldo do corpo docente da instituição, representam a ciência oficial. Foram analisadas as teses defendidas de 1833 a 1940 e selecionadas cerca de $20 \%$ que trataram de temas relativos à sexualidade e à reprodução.

A partir de sua classificação por temas como puberdade, menstruação, menopausa, amor, vida sexual e casamento, perturbações e desvios femininos, formas de tratamento, a autora procura detectar como as teses brasileiras tratavam a diferença sexual. Encontra aí, entre outras coisas, que as diversas fases da vida das mulheres eram vistas como relacionadas ao cumprimento de sua missão reprodutiva; ou que problemas nos órgãos sexuais eram considerados causadores de desvios psíquicos e comportamentais; ou mesmo como era difundida a idéia de uma propensão natural das mulheres para as perversões sexuais. Os tratamentos também seguiam esta orientação, propondo, por exemplo, a prática da ovariotomia para mulheres com desvios psíquicos.

O estudo do caso brasileiro completa-se com a análise da atuação do médico italiano Abel Parente, dono de uma clínica especializada em esterilização no Rio de Janeiro. O fato de ter mantido o consultório mais luxuoso da cidade, e o registro de confraternizações que realizava com suas pacientes, mostram a boa receptividade que este médico parece ter tido junto a parcela da população feminina. No entanto, sua atuação também motivou forte controvérsia no meio médico. De um lado, estavam médicos da Sociedade Brasileira de Higiene, com suas fortes críticas, não apenas à atuação do médico, como à esterilização em geral, 
Uma ciência da diferença...

considerada como um caminho para a maior difusão da prostituição na sociedade brasileira. De outro, médicos do Departamento Sanitário, que defendiam o uso de formas científicas de esterilização como meio de controle da procriação.

Como a autora enfatiza, este caso ilustra bem o caráter polêmico das práticas de esterilização, nestes anos tão presentes também nos países europeus, em um contexto marcado pelo conceito da conformação biológica da mulher à reprodução.

Concluindo, como historiadora da ciência, quero ressaltar duas contribuições do livro.

Inicialmente, para a historiografia da medicina no Brasil, pelo estudo cuidadoso de teorias e práticas que se difundiram no país no período estudado.

Considero ainda este estudo bastante instrutivo, por desvelar o processo histórico de construção de conceitos sobre a diferença sexual, muitos dos quais, naturalizados, ainda marcam presença neste início do século XXI. 